\title{
Effects of mechanical stimuli on structure and organization of bone nanocomposites in rats with glucocorticoid-induced osteoporosis
}

\author{
Nazar M. Kostyshyn ${ }^{1}$, Mechyslav R. Gzhegotsky ${ }^{1}{ }^{1}$, Liybov P. Kostyshyn ${ }^{2}$, Stepan I. Mudry ${ }^{3}$ \\ ${ }^{1}$ Department of Normal Physiology, Danylo Halytsky Lviv National Medical University, Lviv, Ukraine; ${ }^{2}$ Department of \\ Toxicological and Analytical Chemistry, Danylo Halytsky Lviv National Medical University, Lviv, Ukraine; ${ }^{3}$ Department \\ of Metal Physics, Ivan Franko National University, Lviv, Ukraine \\ E-mail: kostyshyn.nm@gmail.com
}

Objective. Clinical use of glucocorticoids is a frequent cause of secondary osteoporosis, which reduces the mineral density of bones and results in pathological fractures. Mechanical stimulation as non-physiological high-frequency vibration with low acceleration prevents the loss of a crystalline component and stimulates the anabolic remodeling of the bone. The aim of the present research was to assess the impact of mechanical vibration on the bone structure in rats, which received glucocorticoids.

Methods. Wistar rats were randomized into three groups: Vehicle control (Veh), Methylprednisolone sodium succinate (Mps), and Mps combined with whole-body vibration (WBV). Rats of Mps+WBV and Mps groups received $3 \mathrm{mg} / \mathrm{kg} /$ day of methylprednisolone every other day for 24 weeks and rats of Veh group received $0.9 \%$ saline (sodium chloride). The group of rats Mps+WBV was subjected to WBV for 30 minutes per day for five days a week with parameters $0.3 \mathrm{~g}$ and frequency $50 \mathrm{~Hz}$. Relative amount of crystalline component and collagen in the bones was determined by X-ray diffraction (XRD) and calcium level - by atomic absorption spectroscopy. Bone tissue metabolism was assessed by determining the concentration of markers, in particular osteocalcin and Tartrate-resistant acid phosphatase (TRAP5b).

Results. Glucocorticoids induced a considerable increase in the rats body mass $(+13 \%)$ and decreased the content of mineral component in the femoral neck (-17\%) in Mps group compared with Veh. The process of the bone metabolism was significantly accelerated, which is proven by an increased level of remodeling markers. It should be mentioned that WBV did not allow significant decrease in mineral component of the bone to 16th week of the experiment compared with Mps group, although these parameters did not achieve the indices in the Vehicle control group (-10\%). Our investigation allows to suggest that mechanical high-frequency vibration of low intensity can partially inhibit the harmful consequences of glucocorticoids on bone structure in rats. Despite the positive impact of vibration on the bone tissue after Mps introduction in the 8th-16th week, this influence was not statistically reliable in the 24th week of the experiment.

Conclusions. The results of our investigation on animal model indicate that non-physiological vertical mechanical vibrations are an effective means to prevent loss of a mineral bone component during treatment with glucocorticoids.

Key words: glucocorticosteroids, whole body vibration, bone remodeling, bone mineral density, osteoporosis, bone nanocomposites, $\mathrm{X}$-ray diffraction 
Glucocorticoids are widely used in medical practice for anti-inflammatory and immunosuppressive therapy of many systemic diseases. However, these medicines are characterized by numerous side effects in long-lasting treatment. Loss of mineral bone density caused by the action of glucocorticoids is the most common cause of secondary osteoporosis that results in pathological fractures and worsening of a patient's condition due to the long-lasting immobilization (Musumeci et al. 2013; Pichler et al. 2013; Lin et al. 2014). Results of a mineral densitometry of the bones prove that in over $50 \%$ of patients, who were subjected to continuous glucocorticoid therapy, osteoporosis was developed. The risk of fractures increases already in 2-4 months after the onset of therapy with such medicines (Golovach 2015). It is known that pathological fractures are not always associated with the loss of bone mineral mass and it can depend on a probable impairment of microarchitectonics of the bone tissue (Compston 2001; Rey at al. 2009; Khosla et al. 2018; Nakajima et al. 2020). At present, pathophysiology of osteoporosis, caused by glucocorticoids, has not been studied completely, but the last reports have indicated an impairment in the bone balance, caused by apoptosis of osteocytes and osteoblasts and increase in life span of osteoclast precursors, which promotes rapid destruction of bone structure (Vandewalle et al. 2014).

Experimental investigations have shown that mechanical loads on the bone, on the contrary, can be anabolic, regulating life span of osteocytes and inhibiting differentiation of osteoclasts (McGeeLawrence et al. 2017; Minematsu et al. 2019; Cardoso et al. 2020; Etemadi et al. 2020; Kakihata et al. 2020; Portier et al. 2020). Osteocytes, which are present in bone matrix, are subjected to mechanical influence and send signals to osteoblasts. Mechanosensitive ion channels Piezo are activated by whole body vibration via oscillations of intracellular fluid in osteocytes and osteoblasts, which can result in their activation and increase in bone mass (Cahalan et al. 2015; Fotiou et al. 2015; Choi et al. 2019). It is explained by the fact that bone tissue metabolism can be regulated by mechanical loads, including non-physiological vibration. A number of authors have reported that non-physiological high-frequency vibration allowed preventing the loss of mineral bone mass in ovariectomized rats and appearance of osteoporosis (Huang et al. 2014; Gruber et al. 2019; Li et al. 2019; Wuestefeld et al. 2020).

Thus, in order to understand the peculiarities of the bone composition at tissue level, it is necessary to investigate the structure, which is presented by elastic fibers and mineral component and their organization at the micro- and nano-structure levels. It will help to understand the mechanisms of mineral mass loss resulting in changes of bone properties, in particular rigidity and strength. In the recent years, the methods of X-ray diffraction have provoked a significant interest in the experimental medicine as an instrument for the investigation of the bone nanostructure. In our experiment, we used X-ray diffraction for the study of structural and mechanical properties of the mineral crystallites and collagen fibers in the samples of rats' femoral neck investigating crystalline lattices and correlation of the components (Clark and Iball 1957; Rogers and Daniels 2002; Tadano and Giri 2012; Bunaciu et al.2015; Piga et al.2013; Schuster et al. 2020).

The aim of our investigation was to assess the bone remodeling and mineral structure of femoral neck in experimental rats under conditions of continuous glucocorticoid therapy and influence of highfrequency non-physiological vibration.

\section{Materials and methods}

Animal model. The experimental study was performed on 54 male Wistar rats with body mass of $180-200 \mathrm{~g}$, kept in the same vivarium conditions. All animal experiments were conducted in compliance with bioethical principles per the provisions of the European Convention for the Protection of Vertebrate Animals used for Experimental and Other Scientific Purposes. Ethics Commission Report №10, 16.12.2019, LNMU. The experimental rats were divided into 3 groups, 18 rats in each: vehicle control group (Veh) - standard vivarium conditions, I experimental group - methylprednisolone sodium succinate (Mps, (SOLU MEDROL), II experimental group - methylprednisolone sodium succinate + whole body vibration (MPS+WBV). All animals were kept in equal conditions (temperature and light), water and food were available ad libitum. (Figure 1A). After the 8 , the 16 and the $24^{\text {th }}$ week, six animals from each group were removed from the experiment by decapitation under urethane general intraperitoneal anesthesia at $0.3 \mathrm{~g} / \mathrm{kg}$ (Severs et al. 1981).

Whole-body vibration. Vertical vibration oscillations were modeled using a 250W APC Rain-60 vibration pump with the maximum pressure of 7 bar and a voltage regulator of the AFC-120 model (Shevchuk et al. 2013; Nykyforov et al. 2019). A vibrating platform with the container, where the experimental group of rats was placed, was attached to the stem of the vibrating pump. In all cases, it was equal to $1.2 \mathrm{~mm}$. The level of vibration acceleration was the 


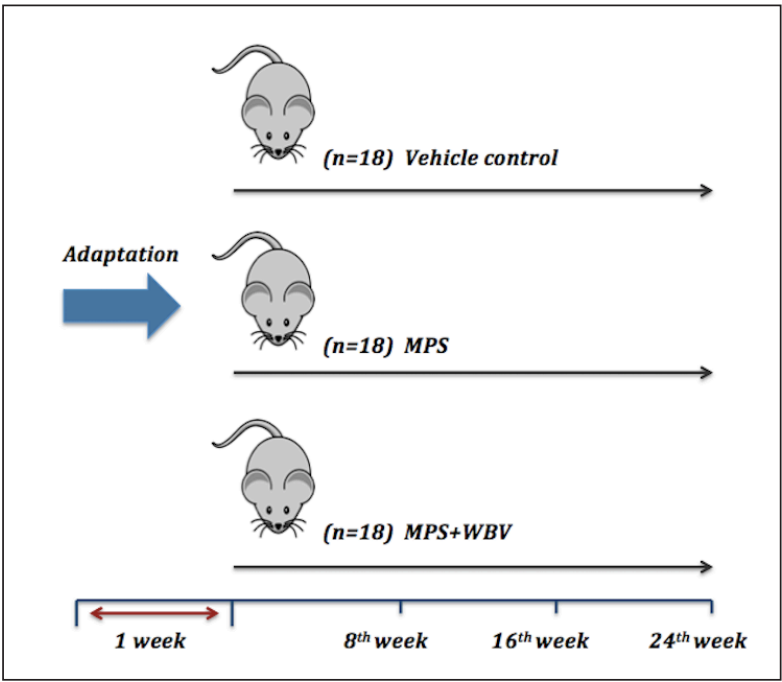

Figure 1. Experimental design. Methylprednisolone sodium succinate (SOLU MEDROL ${ }^{\circ}$ ) was introduced subcutaneously in a dose $3 \mathrm{mg} / \mathrm{kg}$ each other day for 24 weeks (Wang et al. 2002). Vehicle control group was introduced $0.3 \mathrm{ml}$ of physiological solution $(0.9 \% \mathrm{NaCl})$ subcutaneously. All experimental rats were weighed every two weeks.

following: $3.0 \mathrm{~m} / \mathrm{s}^{2}-0.3 \mathrm{~g}$. The rats were exposed to WBV for 30 min, 5 days per week, for 24 weeks.

Determining bone remodeling markers in plasma. Concentrations of cytokines and bone remodeling markers in blood plasma were determined using commercial enzyme-linked immunosorbent assay (ELISA) kits. We determined osteocalcin by $\mathrm{DRG}^{\oplus}$ Mouse Osteocalcin ELISA kit (DRG International, Inc., USA) and Mouse Tartarate Resistant Acid Phosphatase 5b (TRAP5b) by TRACP-5b ELISA kit (MyBioSource, San Diego, CA, USA). All analyses were performed according to the manufacturer's instructions.

$\mathrm{X}$-ray diffraction. To study the ultrastructure of the femur bone mineral component, we used the $\mathrm{X}$-ray diffraction analysis method. The femur was dried at $110^{\circ} \mathrm{C}$ in a drying cabinet. The X-ray diffraction spectra of the samples were obtained on an automated X-ray diffractometer (DRON-3, Russia) in $\mathrm{Cu}$ $\mathrm{Ka}$ radiation $(\lambda=1.5418 \AA$ ) , monochromatized by reflection from a plane (002) of a single pyrographite crystal, mounted on a diffracted beam. We used the Bragg-Brentano focusing scheme $(\theta-2 \theta)$ (Korchevskii 2005; Tadano and Giri 2012). The diffraction patterns were recorded in the continuous movement mode of the detector with an angular velocity of $2 \% \mathrm{~min}$, a constant value of the integration time $\tau=1 \mathrm{~s}$., $\mathrm{X}$-ray tube voltage at $\mathrm{U}=26 \mathrm{kV}$, and anode current at $\mathrm{I}=15 \mathrm{~mA}$.
Atomic absorption spectrometry. To determine calcium in bone tissue, samples were prior mineralized by dry ashing method with further acid extraction. Element composition was determined in prepared samples by the method of atomic absorption spectroscopy on a device C-115PC (Academprybor, Ukraine) using acetyl/air mixture (Pohoryelov et al. 2010). The investigated sample was sprayed in the flame, where cold atom vapor is formed, through which light beams of resonant frequency of calcium pass. Electrons of external membrane take in a part of light beam, further intensity of which is determined by a detector and it is proportional to the concentration of element in flame.

Statistical analysis. Statistical analysis of the data was performed in StatSoft STATISTICA 8.0.360. In the STATISTICA package, the comparison of two average samples of normally distributed features (Student's t-criterion) was implemented in the Basic Statistics/Tables module. The t-test, independent, by variable submodule, was used for two different general summations. One-way ANOVA is implemented in the Breakdown \& One-Way ANOVA submenu of the Basic Statistics and Tables module.

\section{Results}

Anthropometric parameters. Body mass of rats of the I experimental group (Mps) increased in the $8^{\text {th }}$ week to $229.2 \pm 10.3 \mathrm{~g}$, in the $16^{\text {th }}$ week - to $283.5 \pm 8.4 \mathrm{~g}$ and in the $24^{\text {th }}$ week - to $310.2 \pm 12.3 \mathrm{~g}$, indicating statistically significant weight gain compared with the control group $(\mathrm{p}<0.01)$. In group II (Mps+WBV), weight increased to $224.3 \pm 8.5 \mathrm{~g}(\mathrm{p}<0.01), 262.4 \pm 9.4 \mathrm{~g}$ $(\mathrm{p}<0.01)$ and to $289.7 \pm 9.7 \mathrm{~g}(\mathrm{p}<0.01)$ in the $8^{\text {th }}-16^{\text {th }}-$ $24^{\text {th }}$ week, respectively.

Bone remodeling markers in plasma. Bone remodeling was assessed by the levels of bone markers of TRAP5b type and osteocalcin in rats in the $8^{\text {th }}$, $16^{\text {th }}$ and $24^{\text {th }}$ week of the investigation. It should be mentioned that activity of osteoclasts increased under the influence of Mps, which is confirmed by elevated concentration of TRAP5b, while function of osteoblasts decreased (reduced level of osteocalcin). Elevation of osteocalcin level $(\mathrm{p}<0.01)$ was observed in the $8^{\text {th }}$ week in rats of group II (Mps+WBV) compared with the rats, which received only Mps $(\mathrm{p}<0.01)$ and control group $(\mathrm{p}<0.01)$. Besides, the level of this marker remained approximately within the same ranges in the $16^{\text {th }}$ and $24^{\text {th }}$ week of the experiment (Figure 2, Table 1).

The amount of TRAP5b in blood serum of rats, which received glucocorticoids and WBV almost 
returned to norm in the $16^{\text {th }}$ week of investigation, however, differed significantly in animals, which received glucocorticoids in the $8^{\text {th }}$ and $24^{\text {th }}$ weeks $(\mathrm{p}<0.01)$. Osteocalcin level in blood serum of rats in the first and the second groups, which received glucocorticoids and WBV, was significantly higher in the $8^{\text {th }}$ and $16^{\text {th }}$ week, than in the rats, which received only glucocorticoids $(\mathrm{p}<0.01)$ and significantly differed from the control group. However, in the $24^{\text {th }}$ week of the investigation, changes were statistically insignificant.

X-ray diffraction. Quantitative composition, correlation of crystalline and amorphous phase of the bone is determined by the presence of diffuse halo on small angles of diffusion, particularly on the area of angles $2 \theta=15-37.5^{\circ}$. Diffraction pattern was distributed into separate maximums, which corresponded to amorphous and crystalline phases of the bone. An example of such distribution is given in Figure 3. Background of the diffraction pattern in this interval of diffusion angles was approximated by linear function. Volume fraction of amorphous phase was determined by the formula: $\mathbf{X}=\mathbf{I} \mathbf{a} / \mathbf{I}$, where: Ia - integrated intensity of amorphous phase, I - full integrated intensity.

Average size of crystallites was determined by Debye-Scherrer equation by broadening of diffraction maximum (002): $L=\lambda /[\beta \cos (\theta)]$, where $\lambda=0.15148$ $\mathrm{nm}$ - wavelength of X-ray radiation, $\beta$ - physical half the maximum (002), $2 \theta$ - diffraction angle of reflection (002) of crystalline phase.

In addition to determining the nature of bone mineral phase, this method plays an important role in interpreting the structure of the main protein component of the bone - collagen.

Diffraction patterns of bone minerals are presented in Figure 3. Peaks represent diffraction from crystal lattices. Periodic location of atoms in mineral crys- tals and spacing of the region overlapping spaces in collagen fibers enables to use X-ray diffraction efficiently for investigation of bone nanostructure in the experiment. XRD of crystalline phase contains more information about its structure. The peaks, presenting spaces of lattices, are characterized depending on their arrangement, crystallinity and order of crystals. However, mineral particles in the bone are different forms of apatite, particularly hydroxyapatite, which have lower crystallinity. Thus, distinct peaks are absent in diffraction profiles of bone mineral crystals, which have characteristics similar to apatite crystals.

Results of calculations of crystalline and amorphous phase of bone tissue of rat's femoral neck are

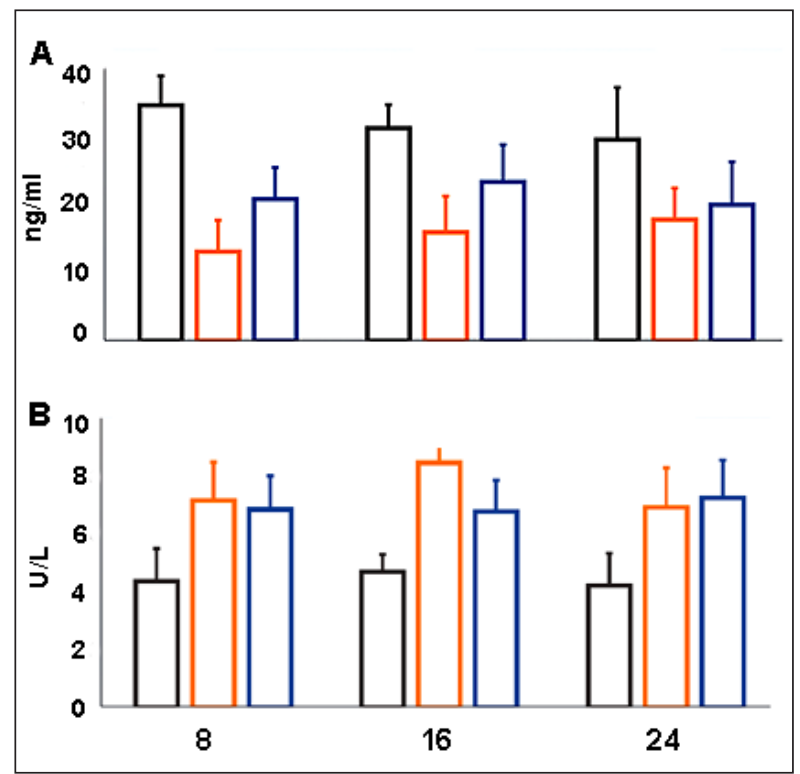

Figure 2. (A) Osteocalcin $(\mathrm{ng} / \mathrm{ml})$ and (B) tartarate resistant acid phosphatase $5 \mathrm{~b}$ (TRAP5b) (U/L) serum levels of mice at $8^{\text {th }}, 16^{\text {th }}$ and $24^{\text {th }}$ weeks.

- MPS+WBV

Table 1

Quantitative analysis of bone formation (osteocalcin) and resorption (5b-isoform of tartrate-resistant acid phosphatase).

\begin{tabular}{|c|c|c|c|c|c|c|c|}
\hline \multirow{2}{*}{ Group } & & \multicolumn{2}{|l|}{ 8th week } & \multicolumn{2}{|l|}{ 16th week } & \multicolumn{2}{|l|}{ 24th week } \\
\hline & & Mean \pm SEM & SD & Mean \pm SEM & SD & Mean \pm SEM & SD \\
\hline \multirow{3}{*}{$\begin{array}{l}\text { Osteocalcin } \\
(\mathrm{ng} / \mathrm{ml})\end{array}$} & Vehicle & $36.4 \pm 2.04$ & 4.56 & $32.77 \pm 1.76$ & 3.76 & $31.15 \pm 3.55$ & 7.95 \\
\hline & MPS & $13.7 \pm 2.22^{*}$ & 4.96 & $16.17 \pm 2.47^{\star}$ & 5.52 & $18.67 \pm 2.18^{\star *}$ & 4.88 \\
\hline & MPS+WBV & $21.77 \pm 2.19^{\star}$ & 4.90 & $24.48 \pm 2.63^{\star *}$ & 5.88 & $20.98 \pm 2.99^{\star *}$ & 6.69 \\
\hline \multirow{3}{*}{$\begin{array}{l}\text { TRAP-5b } \\
(\mathrm{U} / \mathrm{L})\end{array}$} & Vehicle & $4.36 \pm 0.49$ & 1.10 & $4.66 \pm 0.27$ & 0.59 & $4.21 \pm 0.50$ & 1.12 \\
\hline & MPS & $7.15 \pm 0.58^{*}$ & 1.30 & $8.46 \pm 0.45^{*}$ & 1.00 & $6.90 \pm 0.62^{*}$ & 1.38 \\
\hline & MPS+WBV & $6.85 \pm 0.50^{*}$ & 1.14 & $6.75 \pm 0.48^{*}$ & 1.07 & $7.23 \pm 0.58^{\star}$ & 1.30 \\
\hline
\end{tabular}

${ }^{*} \mathrm{p}<0.01 ;{ }^{*} \mathrm{p}<0.05$ compared to control group (Vehicle). Abbreviations: Vehicle - vehicle control group; MPS - I experimental group (methylprednisolone sodium succinate); MPS+WBV - II experimental group (methylprednisolone sodium succinate + whole body vibration). 

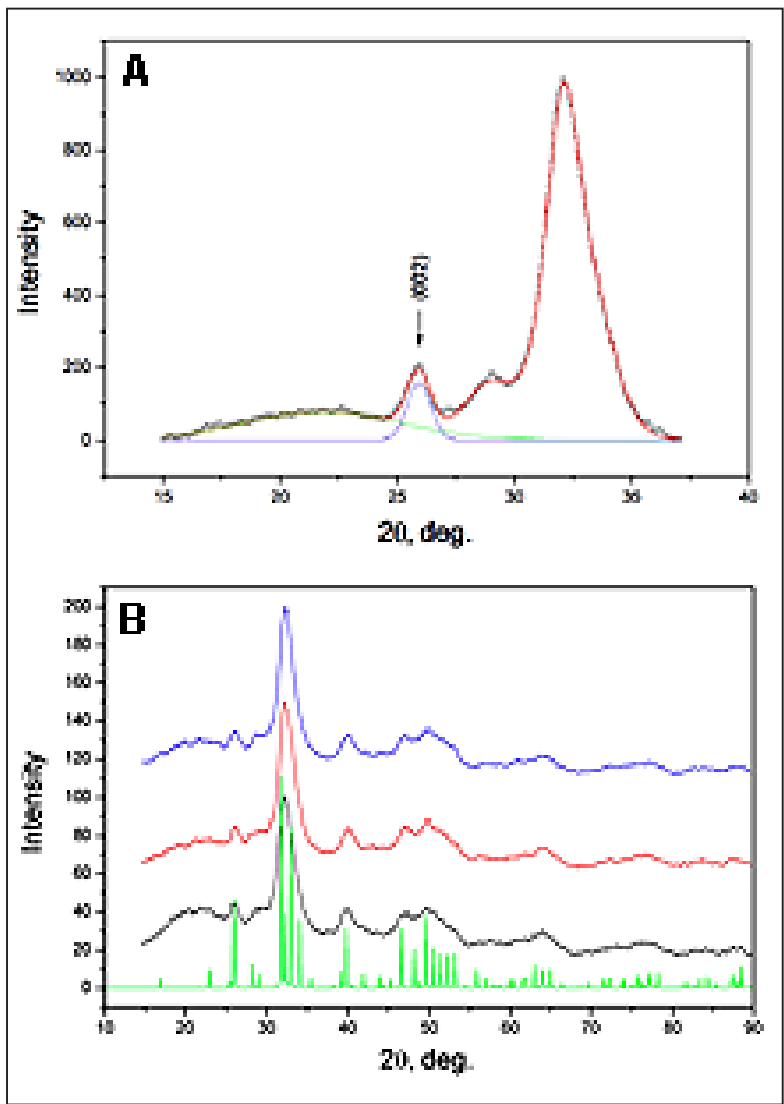

Figure 3. (A) The diffractogram is presented as superposition of maximums: dots - experimental data, red line - approximate curve, blue line - profile of maximum (002) of a crystalline phase, green line - profile of maximum of amorphous phase. (B) The diffraction spectra of the samples were obtained on an automated $\mathrm{X}$-ray diffractometer in $\mathrm{Cu} \mathrm{Ka}$ radiation by monochromatic reflection from the plane (002) of a single graphite crystal mounted on a diffracted beam. The spectra were recorded in the continuous moving mode of the detector at the $2 \mathrm{deg} / \mathrm{min}$ speed. To determine the integral intensity of the hydroxyapatite reflex, we chose a reflex in $30-37^{\circ}$ angular range since its intensity is the highest. Although this reflex consists of four reflexes of hydroxyapatite with Miller indices (211); (112); (300); (202), the diffraction angles from crystallographic planes with these indices are close to $31,741^{\circ} ; 32,179^{\circ}$; $32,868^{\circ}$ and 34,045 . presented in Figure 4. As it is seen in the image, on sample spectra (Figures $4 \mathrm{~A}, \mathrm{C}, \mathrm{D}$ ) at $8^{\text {th }}, 16^{\text {th }}$ and $24^{\text {th }}$ week, volume fraction of crystalline phase slightly increases in rats of the control group.

A reliable decrease in absolute amount of hydroxyapatite is observed in the I experimental group (Mps) in the $8^{\text {th }}-16^{\text {th }}$ week, and stabilization of this process occurs in the $24^{\text {th }}$ week compared with the control group. Increase in volume fraction of amorphous phase (collagen) is also observed, indicating accelerated remodeling (Figure 5). Statistically reliably higher $(\mathrm{p}<0.05)$ values of crystalline phase were observed in rats, which were introduced methylprednisolone and exposed to vibration, compared with the indices in control group during the same period. WBV prevented early loss of mineral component after continuous introduction of methylprednisolone during 8-16 weeks $(\mathrm{p}<0.05)$. It should be mentioned that despite positive impact of vibration on bone tissue of rats with glucocorticosteroid osteoporosis (8-16 weeks), this influence was not statistically reliable in the $24^{\text {th }}$ week (Figure 4 ).

Table 2 presents quantitative characteristics of calcium in investigated samples of femoral bone. In the $8^{\text {th }}$ week of the experiment, we observed decrease in calcium amount in the samples of the first investigated group by $25 \%$ compared with the control group $(\mathrm{p}<0.05)$. In the second investigated group, reduction of quantitative indices of calcium were recorded, however, the value was by $14.6 \%$ lower compared with the control group $(\mathrm{p}<0.05)$ and by $10 \%$ - compared with the first group $(\mathrm{p}<0.05)$. In the $16^{\text {th }}$ and $24^{\text {th }}$ week of observations, calcium mass decreased only in the first investigated group $(\mathrm{p}<0.05)$. Most likely, it indicates continuation of bone remodeling with high activity of osteoclasts and osteoblasts, which results in loss of mineral mass of the femur. On the $16^{\text {th }}$ day, dynamics of calcium loss constituted $29.6 \%$ for group I and $20.6 \%$ for group II compared with control group. In the $24^{\text {th }}$ week, these values consti-

Table 2

Content of calcium $(\mathrm{mg} / \mathrm{g})$ in fragments of the femoral neck in experimental animals.

\begin{tabular}{|c|c|c|c|c|c|c|}
\hline \multirow{2}{*}{ Group } & \multicolumn{2}{|c|}{ 8th week } & \multicolumn{2}{|c|}{ 16th week } & \multicolumn{2}{|c|}{ 24th week } \\
\hline & Mean \pm SEM & SD & Mean \pm SEM & SD & Mean \pm SEM & SD \\
\hline Vehicle & $96.02 \pm 2.60^{*}$ & 5.81 & $94.72 \pm 4.33^{*}$ & 9.68 & $98.43 \pm 5.59^{*}$ & 12.49 \\
\hline MPS & $71.96 \pm 4.64^{*}$ & 10.39 & $67.61 \pm 3.86^{*}$ & 8.64 & $61.88 \pm 3.55^{*}$ & 7.93 \\
\hline MPS+WBV & $82.06 \pm 4.40^{\star *}$ & 9.83 & $75.39 \pm 4.47^{*}$ & 10.0 & $65.27 \pm 4.07^{*}$ & 9.10 \\
\hline
\end{tabular}

${ }^{\star} \mathrm{p}<0.01 ;{ }^{* *} \mathrm{p}<0.05$ compared to control group (Vehicle). Abbreviations: Vehicle - vehicle control group; MPS - I experimental group (methylprednisolone sodium succinate); MPS+WBV - II experimental group (methylprednisolone sodium succinate + whole body vibration). 


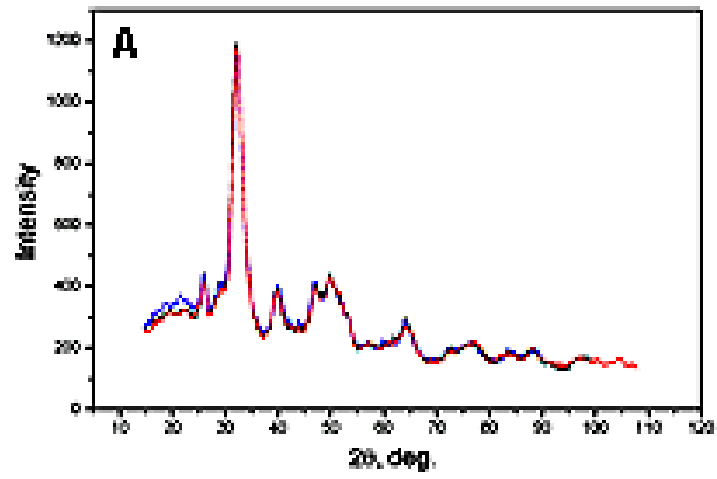

B
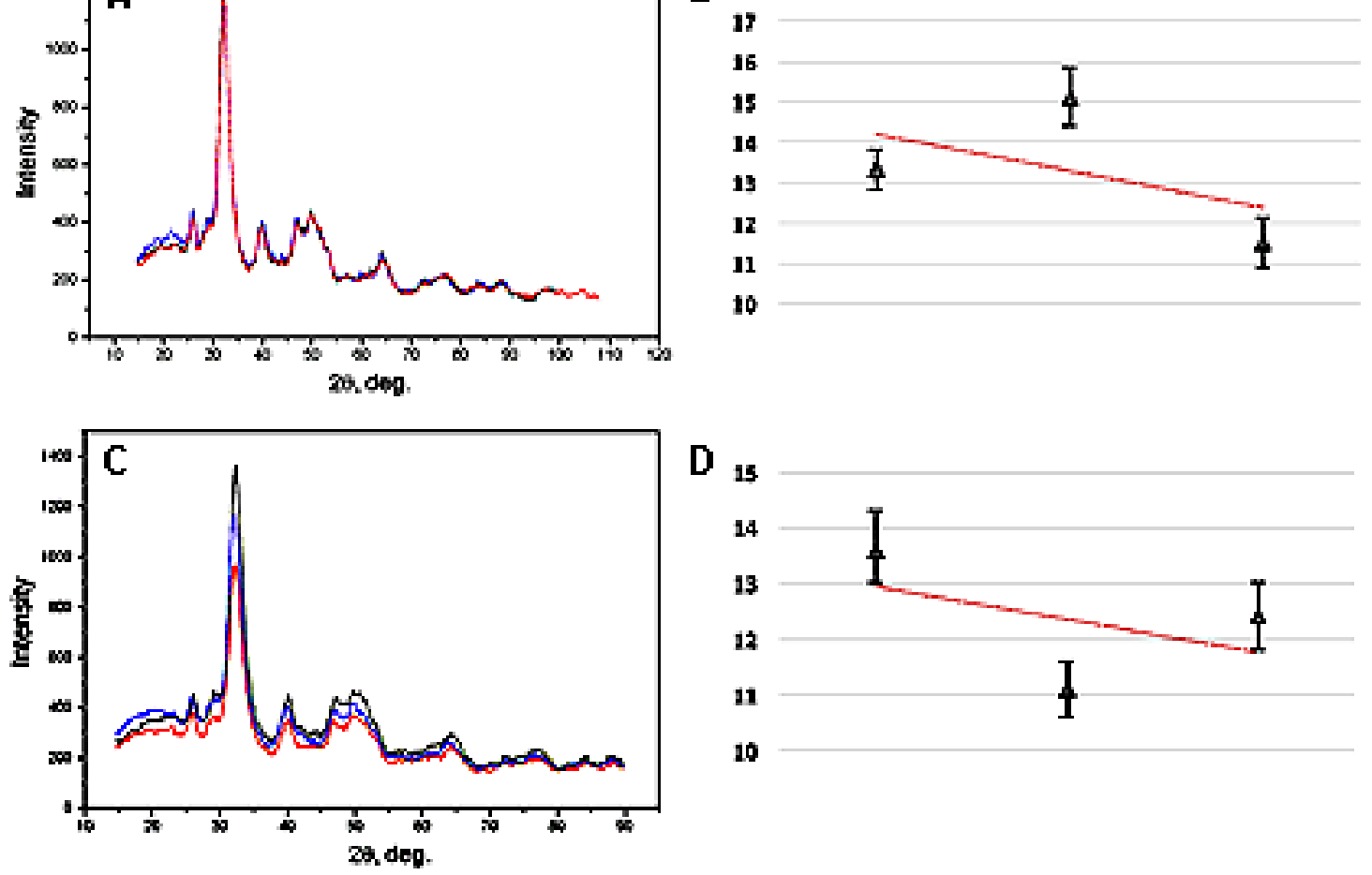

10

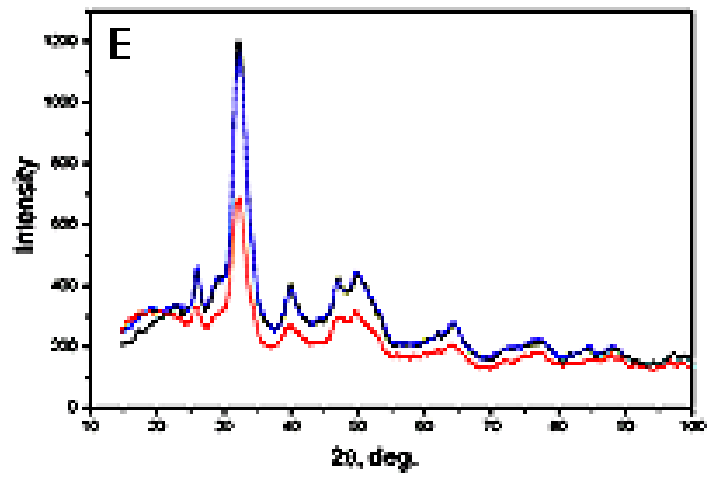

F

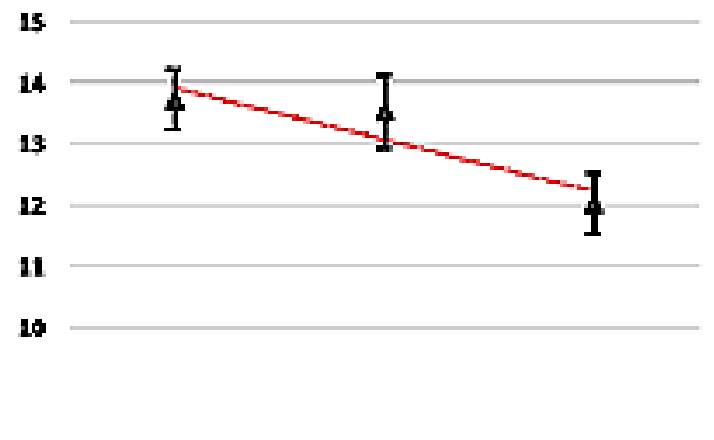

Figure 4. Diffraction patterns of femoral neck fragments in Vehicle control $(A, B)$, Mps $(C, D) M p s+W B V(E, F)$ at $-8^{\text {th }},-16^{\text {th }}$, $-24^{\text {th }}$ week. The images show mineralization level of the femoral neck and dependence of grain sizes of crystalline phase. MPS introduction reduces relative amount of bone mineral phase, and WBV leads to inhibition of crystalline component loss even to the level of control group in the $8^{\text {th }}$ and $16^{\text {th }}$ weeks.

tuted $37 \%$ and $33.7 \%$, respectively. Moreover, calcium loss under the influence of high-frequency vibration significantly slowed down starting from the $8^{\text {th }}$ week $(\mathrm{p}<0.05)$ and to the $16^{\text {th }}$ week of the experiment $(\mathrm{p}<0.05)$. In the $24^{\text {th }}$ week this index was statistically insignificant ( $p>0.05)$.

The obtained experimental data correlate with the levels of remodeling markers in the rats' blood.
Loss of quantitative mineral mass of the femoral neck induced by glucocorticoids is associated with increase in the marker of bone resorption TRAP $5 \mathrm{~b}$ $(64 \%, \mathrm{p}<0.05)$ and decrease in the marker of osteocalcin formation in the bone $(62.4 \%, \mathrm{p}<0.05)$ in the $8^{\text {th }}$ week compared with the control group (Figure 2). Analysis of bone hydroxyapatite by XRD in a group of rats, which were injected glucocorticoids, showed 


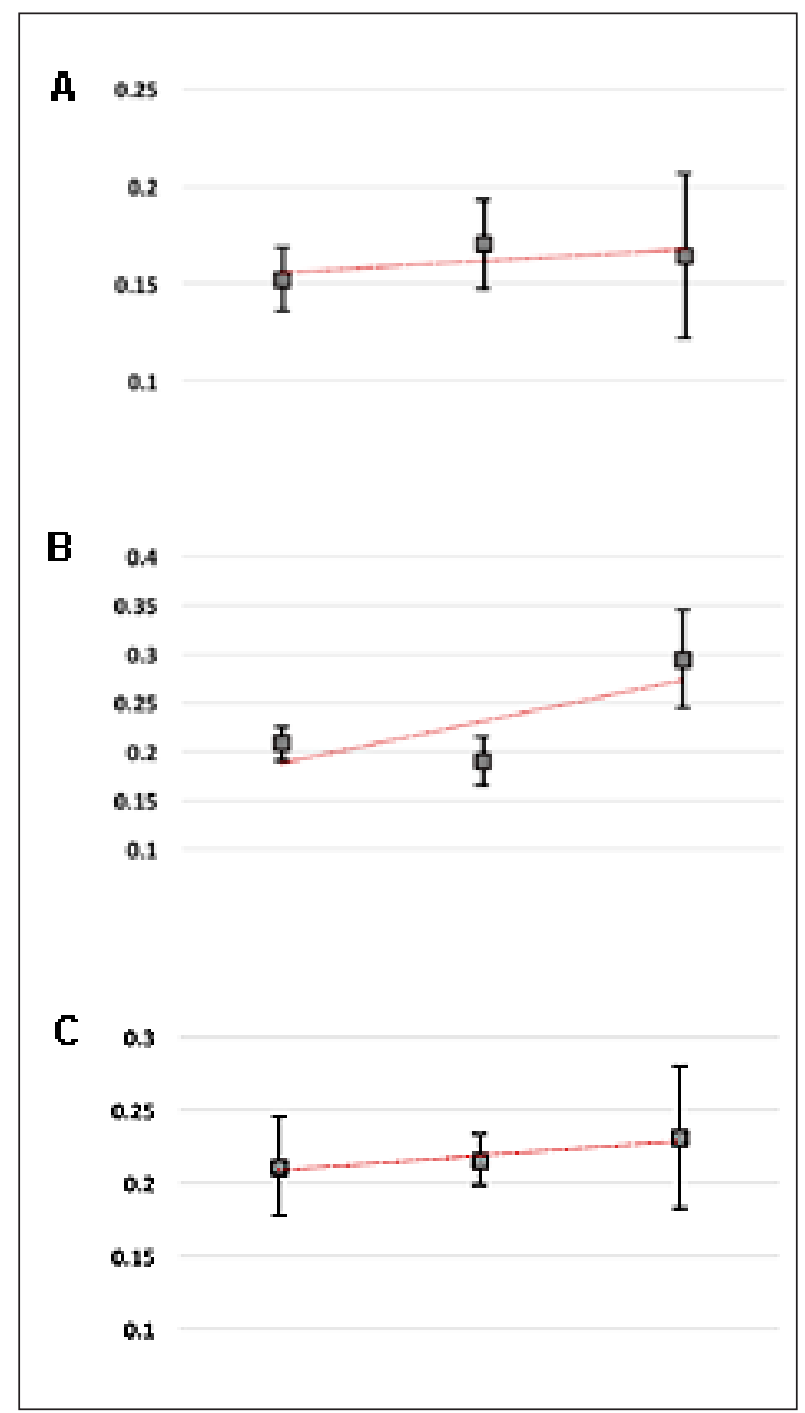

Figure 5. Dependence of volume fraction of amorphous phase $(\mathrm{X}, \mathrm{am})$ in samples of control group (A), Mps (B) and group Mps+WBV (C). Linear extrapolation of the data indicates the tendency to increase in the content of amorphous phase almost in all samples, however, this value is the highest in the I experimental group, proving acceleration of bone remodeling and rapid loss of mineral component.

reduction of crystalline component by $10 \%$ in the $8^{\text {th }}$ week compared with the control group. TRAP5b index increased in the $16^{\text {th }}-24^{\text {th }}$ week by 81.5 and $71.7 \%$, respectively, and osteocalcin level decreased by 25.1 and $32.3 \%$, respectively. Amount of hydroxyapatite in these groups decreased to $17 \%$ by the end of the experiment. Influence of WBV on rats, which were introduced glucocorticoids in the $8^{\text {th }}-16^{\text {th }}$ weeks, showed slight decrease in the volume of crystalline component, which was by $10-12 \%$ lower than in the animals receiving placebo $(\mathrm{p}<0.05)$ and by $7 \%$ higher than in the animals treated with glucocorticoids $(p<0.05)$. It is seen in the charts that besides the aforementioned effects, collagen metabolism increases both in group I and group II, indicating accelerated remodeling and explains rapid BMD loss.

\section{Discussion}

Our investigation proved that non-physiological low-intensity and high-frequency vibration $(50 \mathrm{~Hz}$, $0.3 \mathrm{~g}$ ) can inhibit some side influences of glucocorticoids on bone structure in rats and their metabolism. Using XRD, we established that continuous administration of glucocorticoids significantly reduces the amount of crystalline component in bone tissue. However, in rats (II group), which were additionally exposed to vibration and experienced side influence of methylprednisolone, crystalline parameters of bones did not differ substantially even to the $16^{\text {th }}$ week of the experiment. Besides, mechanical oscillations of the whole body also enabled to preserve by $30 \%$ more of mineral mass compared with quantitative indices in the first experimental group. It can be concluded that increase in amount of mineral bone mass occurs in the process of remodeling, in particular, stimulation of osteocytes and osteoblasts. To confirm changes in the remodeling of rats' skeletons, we applied laboratory markers TRAP5b and osteocalcin.

It is important to study not only the loss of mineral phase of the bone tissue, but also diagnostics of collagen fibers, since combination of these components gives strength to the bone. It is obvious that not only mineral bone density characterizes its strength as a whole (Tadano and Giri 2012; Schuster et al. 2020). The femoral neck was used in our investigation, because the majority of pathological fractures occur in this region. In addition to mineral density, there are other characteristics, associated with the mineral crystallites, namely, their shape, size, orientation etc., which can have direct impact on the mechanical properties of the entire bone tissue. Information on the condition of the main structural unit of the bone, i.e., mineral-collagen composite, provides better understanding of volume structure and strength of the bone tissue. Despite a number of advantages of XRD method, it is limited by the presence of numerous scientific laboratories and is has limited use in clinical investigations. However, XRD method is an effective non-destructive technique for establishment of new aspects of bone nanostructure.

The limitations of this study are that we did not consider the amount of mineral component sepa- 
rately in the cortical and trabecular layers of bone. However, the X-ray diffraction method determined not the bone density, but the mineral mass, the structure of the crystal lattice, and the ratio of crystalline and amorphous components.

Similar investigations, described in the works of Judex et al. (2007), have indicated that 28-day whole body vibration for 10 minutes a day with frequency $90 \mathrm{~Hz}(0.15 \mathrm{~g})$ resulted in an accelerated formation of trabecular layer of the bone tissue in rats after ovariectomy. Hulley et al. (2002) have demonstrated that methylprednisolone in the dose $3.5 \mathrm{mg} / \mathrm{kg} /$ day five times a week for nine weeks could reduce the mineral density of bone tissue with impairment of bone remodeling. Other researchers have shown that introduction of methylprednisolone in the dose from $2.5 \mathrm{mg} / \mathrm{kg}$ to $9.0 \mathrm{mg} / \mathrm{kg}$ for $8-12$ weeks causes osteopenia in rats and can be used for its modeling (Iwamoto at al. 2006; Kondo at al. 2006; Oxlund at al. 2006; Kimura at al. 2007). Ogashi et al. (2008) have investigated the impact of different methylprednisolone doses for four weeks in various regions of rats' skeletons depending on age and demonstrated vast variability of reactions in groups. There are also results (Ogashi at al. 2008), which have indicated that glucocorticoids can cause anabolic effect in certain areas of the skeleton. In most cases, a reduction in the number of bone trabecules has been observed.

In our investigation, we established that vibration with the high level of acceleration $(0.3 \mathrm{~g}, 50 \mathrm{~Hz})$ changes the bone remodeling in rats after treatment with methylprednisolone. Mechanical loads presented by non-physiological vibration did not result in severe damage to crystal lattice of bone tissue and elastic fibers in early periods and even further slowed down loss of crystalline component. Despite the fact that vibration had a positive impact on the bone tissue in young rats after long-lasting treatment with glucocorticoids, this influence was not statistically reliable in the $24^{\text {th }}$ week. Our data indicate that non-physiological vertical mechanical oscillations are effective means to prevent early loss of mineral density of the femoral neck, which was investigated on animal model. Described vibration effects can be useful for understanding of metabolism in the bones under different life conditions for prevention and correction in treatment of osteopenia with different etiologies and for long-lasting treatment with glucocorticoids.

\section{Acknowledgements}

This work was supported by the Department of Normal Physiology of Danylo Halytsky Lviv National Medical University "Researching the role of systemic and paracrine regulatory mechanisms in providing homeostasis of functional and metabolic parameters of the organism under conditions of adaptation to extreme factors of diverse nature" (state registration number 0116U004510).

\section{References}

Bunaciu AA, Udristioiu EG, Aboul-Enein HY. X-ray diffraction: instrumentation and applications. Crit Rev Anal Chem 45, 289-299, 2015.

Cardoso AL, Frederico EH, Guimaraes CA, Guedes-Aguiar EO, Moreira-Marconi E, Paineiras-Domingos LL, Sa-Caputo DC, Bernardo-Filho M, Asad NR. Long-term effects of mechanical vibration stimulus on the bone formation of Wistar rats: An assessment method based on X-rays images. Acad Radiol 1076-6332,30344-30345, 2020.

Cahalan SM, Lukacs V, Ranade SS, Chien S, Bandell M, Patapoutian A. Piezol links mechanical forces to red blood cell volume. Elife 4, e07370, 2015.

Choi D, Park E, Jung E, Cha B, Lee S, Yu J, Kim PM, Lee S, Hong YJ, Koh CJ, Cho CW, Wu Y, Li N Jeon, Wong AK, Shin L, Kumar SR, Bermejo-Moreno I, Srinivasan RS, Cho IT, Hong YK. Piezol incorporates mechanical force signals into the genetic program that governs lymphatic valve development and maintenance, JCI Insight 4, 125068, 2019.

Compston JE. Sex steroids and bone. Physiol Rev 81, 419-447, 2001.

Clark SM, Iball J. The x-ray crystal analysis of bone. Prog Biophys Biophys Chem 7, 225-253. 1957.

Etemadi Sh M, Hsieh NC, Movahed Mohammadi SS, Momeni S, Razavi SM, Alizargar J. Histological and radiological evaluation of low-intensity pulsed ultrasound versus whole body vibration on healing of mandibular bone defects in rats. Medicina (Kaunas) 56, 457, 2020.

Fotiou E, Martin-Almedina S, Simpson MA, Lin S, Gordon K, Brice G, Atton G, Jeffery I, Rees DC, Mignot C, Vogt J, Homfray T, Snyder MP, Rockson SG, Jeffery S, Mortimer PS, Mansour S, Ostergaard P. Novel mutations in PIEZO1 cause an autosomal recessive generalized lymphatic dysplasia with non-immune hydrops fetalis. Nat Commun 6, 8085, 2015. 
Golovach IY. Obesity-induced osteoarthritis: the multifactorial association and leading role of adipokines, dyslipidemia and mechanical loading. Trauma 16, 70-78, 2015.

Gruber M, Kramer A, Mulder E, Rittweger J. The importance of impact loading and the stretch shortening cycle for spaceflight countermeasures. Front Physiol 10, 311, 2019.

Huang CC, Tseng TL, Huang WC, Chung YH, Chuang HL, Wu JH. Whole-body vibration training effect on physical performance and obesity in mice. Int J Med Sci 11, 1218-1227, 2014.

Hulley PA, Conradie MM, Langeveldt CR, Hough FS. Glucocorticoid-induced osteoporosis in the rat is prevented by the tyrosine phosphatase inhibitor, sodium orthovanadate. Bone 31, 220-229, 2002.

Iwamoto J, Seki A, Takeda T, Sato Y, Yamada H, Shen CL, Yeh JK. Preventive effects of risedronate and calcitriol on cancellous osteopenia in rats treated with high- glucocorticoid dose. Exp Anim 4, 349-318, 2006.

Judex S, Lei X, Han D, Rubin C. Low-magnitude mechanical signals that stimulate bone formation in the ovariectomized rat are dependent on the applied frequency but not on the strain magnitude. J Biomech 40, 1333-1339, 2007.

Kakihata CMM, Peretti AL, Tavares ALF, Wutzke MLS, Ribeiro LFC, Costa RM, Bertolini GRF. Morphometric effects of whole-body vibration on the bone in a rat model of postmenopausal osteoporosis. J Manipulative Physiol Ther 43, 551-557, 2020.

Khosla S, Monroe DG. Regulation of bone metabolism by sex steroids. Cold Spring Harb Perspect Med 8, a031211, 2018.

Li X, Han L, Nookaew I, Mannen E, Silva MJ, Almeida M, Xiong J. Stimulation of Piezol by mechanical signals promotes bone anabolism. Elife 8, e49631, 2019.

Kimura E, Nishioka T, Hasegawa K, Maki K. Effects of bisphosphonate of rats in the growing phase with steroidinduced osteoporosis on the mandible. Oral Diseases 13, 544-549, 2007.

Kondo N, Tokunaga K, Ito T, Arai K, Amizuka N, Minqi L, Kitahara H, Ito M, Naito M, Shu-Ying J, Oda K, Murai T, Takano R, Ogose A, Endo N. High dose glucocorticoid hampers bone formation and resorption after bone marrow ablation in rat. Microsc Res Tech 10, 839-846, 2006.

Korchevskii VV. Numerical simulation of the recording of diffraction lines with the Bragg-Brentano focusing. Crystallogr Rep 50, 354-356, 2005.

Lin S, Huang J, Zheng L, Liu Y, Liu G, Li N, Wang K, Zou L, Wu T, Qin L, Cui L, Li G. Glucocorticoid-induced osteoporosis in growing rats. Calcif Tissue Int 95, 362-373, 2014.

McGee-Lawrence ME, Wenger KH, Misra S, Davis CL, Pollock NK, Elsalanty M, Ding K, Isales CM, Hamrick MW, Wosiski-Kuhn M, Arounleut P, Mattson MP, Cutler RG, Yu JC, Stranahan AM. Whole-body vibration mimics the metabolic effects of exercise in male leptin receptor-deficient mice. Endocrinology 158, 1160-1171, 2017.

Minematsu A, Nishii Y, Imagita H, Sakata S. Whole body vibration at low-frequency can increase trabecular thickness and width in adult rats. J Musculoskelet Neuronal Interact 19, 169-177, 2019.

Musumeci G, Loreto C, Leonardi R, Castorina S, Giunta S, Carnazza ML, Trovaro FM, Pichler K, Weinberg AM. The effects of physical activity on apoptosis and lubricin expression in articular cartilage in rats with glucocorticoid-induced osteoporosis. J Bone Miner Metab 31, 274-284, 2013.

Nakajima K, Matsunaga S, Morioka T, Nakano T, Abe S, Furuya Y, Yajima Y. Effects of unloading by tail suspension on biological apatite crystallite alignment in mouse femur. Dent Mater J 39, 670-677, 2020.

Nykyforov VV, Malovanyy MS, Aftanaziv IS, Shevchuk LI, Strutynska LR. Developing a technology for treating bluegreen algae biomass using vibro-resonance cavitators. Scientific Bulletin of National Mining University 6, 181-188, 2019.

Ogashi T, Hagini H, Fukata S, Tanishima S, Okano T, Teshima R. Influence of glucocorticoid on bone in 3-6- and 12-month-old rats as determined by bone mass and histomorphometry. Mod Rheumatol 18, 552-561, 2008.

Oxlund H, Ortoft G, Thomsen JS, Danielsen CC, Ejersted C, Andreassen TT. The anabolic effect of PTH on bone is attenuated by simultaneous glucocorticoid treatment. Bone 39, 244-252, 2006.

Pichler K, Loreto C, Leonardi R, Reuber T, Weinberg AM, Musumeci G. RANKL is downregulated in bone cells by physical activity (treadmill and vibration stimulation training) in rat with glucocorticoid-induced osteoporosis. Histol Histopathol 28, 1185-1196, 2013.

Piga G, Solinas G, Thompson TJU, Brunetti A, Malgosa A, Enzo S. Is X-ray diffraction able to distinguish between animal and human bones? Journal of Archaeological Science 40, 778-785, 2013.

Pohoryelov MV, Bumeyster VI, Tkach HF, Bonchev SD, Sikora VZ, Sukhodub LF, Danylchenko SM. Macro-and microelements (metabolism, pathology and methods of determination). SymDu 147, 2010. 
Portier H, Benaitreau D, Pallu S. Does physical exercise always improve bone quality in rats? Life (Basel) 10, $217,2020$. Rey C, Combes C, Drouet C, Glimcher MJ. Bone mineral: update on chemical composition and structure. Osteoporos Int 20, 1013-1021, 2009.

Rogers KD, Daniels P. An X-ray diffraction study of the effects of heat treatment on bone mineral microstructure. Biomaterials 23, 2577-2585, 2002.

Schuster L, Ardjomandi N, Munz M, Umrath F, Klein C, Rupp F, Alexander D. Establishment of collagen: hydroxyapatite/BMP-2 mimetic peptide composites. Materials 13, 1203, 2020.

Severs WB, Keil LC, Klase PA, Deen KC. Urethane anesthesia in rats. Pharmacology 22, 209-226, 1981.

Shevchuk LI, Aftanasiv IS, Strogan OI, Starchevskyi VL. Low-frequency veroresonant cavitators: monograph. Lviv Polytechnic Publishing House, 173, Lviv, 2013.

Tadano S, Giri B. X-ray diffraction as a promising tool to characterize bone nanocomposites. Sci Technol Adv Mater 12, 064708, 2012.

Vandewalle SARA, Taes Y, Fiers T, Toye K, Van Caenegem E, Roggen I, Kaufman JM. Associations of sex steroids with bone maturation, bone mineral density, bone geometry, and body composition: a cross-sectional study in healthy male adolescents. J Clin Endocrinol Metab 99, E1272-E1282, 2014.

Wang Y, Ohtsuka-Isoya M, Shao P, Sakamoto S, Shinoda H. Effects of methylprednisolone on bone formation and resorption in rats. Jpn J Pharmacol 90, 236-246, 2002.

Wuestefeld A, Fuermaier ABM, Bernardo-Filho M, da Cunha de Sa-Caputo D, Rittweger J, Schoenau E, Stark C, Marin PJ, Seixas A, Judex S, Taiar R, Nyakas C, van der Zee EA, van Heuvelen MJG, Tucha O. Towards reporting guidelines of research using whole-body vibration as training or treatment regimen in human subjects-A Delphi consensus study. PLoS One 15, e0235905, 2020. 